\title{
Recovery of an Elderly Kwashiorkor Patient by Korean Medicine: A Case Report
}

\author{
Cheon-Hoo Jeon ${ }^{1}$, Sul-Ki Kim ${ }^{1}$, Chang-Gue Son $^{2 *}$ \\ 1Department of Internal Korean Medicine, College of Korean Medicine, Daejeon University \\ ${ }^{2}$ Liver and Immunology Research Center, Oriental Medical College in Daejeon University
}

\begin{abstract}
Objectives: The present study reports case of an elderly kwashiorkor patient who was treated with Korean Medicine. Methods: A 68-year-old female patient with weight loss, general weakness, chills, anorexia, and dizziness after over 100 episodes of diarrhea visited the hospital. Blood tests showed hypoalbuminemia and anemia, and ultrasonography revealed fatty liver disease. The patient was diagnosed with kwashiorkor, and her symptom differentiation was Yang deficiency followed by Both Qi-Blood deficiency. Sayeok-Tang, Soshiho-Tang, Insamyangyeong-Tang, and Gongjin-Dan, herbal drugs, were given to the patient during 40 days of hospitalization.

Results: After 40 days of hospitalization, her symptoms were reduced, and the blood test results improved. Conclusion: This case presents the therapeutic potential of Korean medicine in the treatment of kwashiorkor.
\end{abstract}

Key Words : Kwashiorkor, Protein-energy malnutrition, Korean medicine, Case report

\section{Introduction}

Malnutrition is defined as an imbalance between the supply of nutrients and energy and the body's demand for them to ensure growth, maintenance, and specific functions. ${ }^{1)}$ Protein-energy malnutrition (PEM) is a common form of malnutrition characterized by insufficient protein intake to fulfill the body's needs. ${ }^{2)}$ The prevalence of malnutrition in the elderly varies by clinical setting from $4 \%$ in the community to $32.5 \%$ in rehabilitative/subacute care. ${ }^{3)}$ In the case of Korea, data from the National Health Insurance Service from 2014 to 2018 showed approximately 28,000 cases of PEM, which led to approximately $\$ 5$ million in medical expenses. ${ }^{4)}$ This pattern has not been changed for a decade in Korea.

PEM can be classified as primary and secondary by the cause and as marasmus and kwashiorkor by the period of the disorder. Primary PEM is commonly found in developing countries due to food shortages caused by famine. PEM occurs prevalently not only in developing countries but also in developed countries. ${ }^{5)}$ Secondary PEM is attributed to chronic diseases, such as neurological disorders and inflammatory bowel disease, which cause anorexia and malabsorption. ${ }^{6}$ ) On the other hand, marasmus is a chronic condition of deficit

\footnotetext{
- Received : 3 February $2021 \quad$ - Revised : 16 February 2021

- Accepted : 18 February 2021

- Correspondence to : Chang-Gue Son

Liver and Immunology Research Center, Daejeon Oriental Hospital of Daejeon University

Daedeokdae-ro 176 beon-gil 75, Seo-gu, Daejeon, Republic of Korea

Tel : +82-42-484-6484, Fax : +82-42-470-9005, E-mail : ckson@dju.ac.kr
} 
occurring over months to years, while kwashiorkor is an acute condition of deficit usually occurring over weeks. ${ }^{7)}$ In the clinic, distinguishing between marasmus and kwashiorkor is very important because aggressive nutritional support is recommended for cases of kwashiorkor but increases the risk for metabolic imbalances in marasmus. ${ }^{8)}$

For kwashiorkor, supplying proper nutrition, including micronutrients, is a typical treatment, and advanced kwashiorkor has a poor prognosis, especially in the senile population. ${ }^{9}$ Malnutrition increases the risk of systemic problems, such as respiratory and cardiac problems, and even mortality. ${ }^{10)}$ Regarding elderly patients with kwashiorkor, the reduced physical function and metabolic capacity lead to difficulty recovering despite proper nutritional care. ${ }^{11)}$ There have been several studies on herbal treatments for chronic malnutrition; ${ }^{12-14)}$ however, no studies on kwashiorkor exist.

The study demonstrates the therapeutic potential of Korean medicine for kwashiorkor in an elderly patient who developed the condition during diarrhea therapy for severe atopic dermatitis. This case corresponds to the case Report Guideline (CARE guidelines) and was approved by the Institutional Review Board of Daejeon Korean medicine Hospital (DJDSKH-20-E-28-1).

\section{Medical history and examination}

A 67-year-old woman had been generally healthy before she began suffering from atopic dermatitis at 42 years of age. This patient had received conventional treatments, including systemic steroids, for the past 25 years, but these were ineffective. Recently, the patient had applied a diarrhea therapy (so-called "detox using lemon juice") for 4 weeks, which led to over 100 episodes of severe diarrhea (3-4 times daily) with a weight loss of $6 \mathrm{~kg}$ from $50 \mathrm{~kg}$. This diarrhea therapy slightly decreased the itching symptoms during the period, which then returned. Although the diarrhea was stopped, the patient complained of severe anorexia, tiredness, general weakness and chills for 2 weeks. The amount of food intake had also decreased. She felt difficulty walking by herself due to her weakened condition and dizziness. The patient thus visited a Korean medicine hospital and was hospitalized (December 31, 2018). The patient had no previous history of disorders, alcohol use, or cigarette use and no specific family history.

The patient's appearance was very thin, with a body mass index (BMI) of 17.3. Her skin was severely dry and flaky, with eczema and inflammation and even hair loss. Also, she had swollen features on both feet. Laboratory tests were conducted, including complete blood count (CBC) analysis, biochemistry, immunology, urine analysis and abdominal sonography. The patient had anemia (hemoglobin, 10.5; normal range, 12.0-16.0 g/dl), eosinophilia (14.0\%; normal range, $0-5 \%)$, a remarkably high level of serum immunoglobulin $\mathrm{E}$ (IgE) (20955 IU/ml; normal range, < $100 \mathrm{IU} / \mathrm{ml}$ ), a lowered serum albumin level $(1.9 \mathrm{~g} / \mathrm{dL}$; normal range, 3.5-5.2 $\mathrm{g} / \mathrm{dl}$ ), and a slightly elevated serum alkaline phosphatase level (ALP, 149 IU/L; normal range, 40-129 IU/L) but mild fatty liver on ultrasonography. A decreased blood pressure (100/61 mmHg) and rapid heart rate (96 beats/ minute) were observed, but the patient's electrolyte levels were sustained within the normal range. 


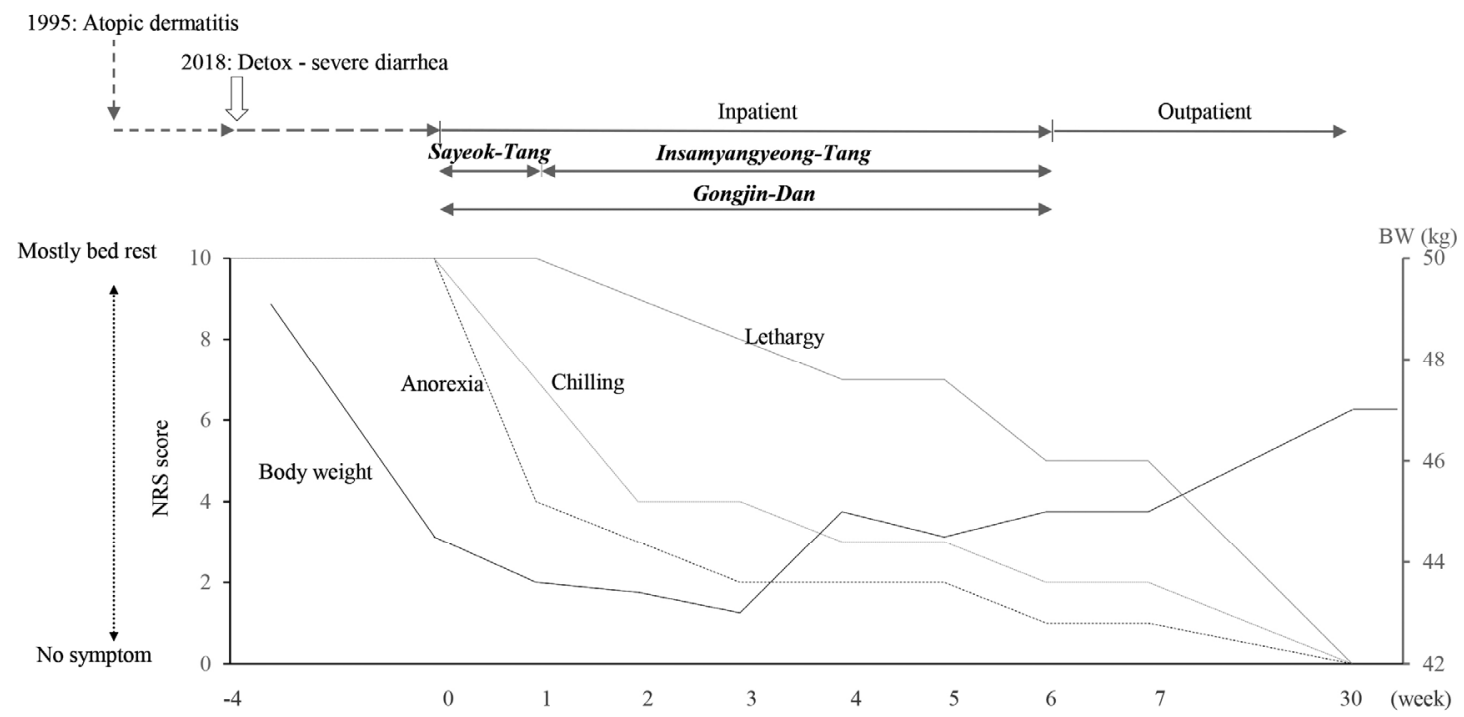

Fig. 1. Summary of clinical outcome and treatment course.

Based on her history and symptoms, we finally diagnosed her with kwashiorkor. Regarding the Korean medicine diagnostic method, the patient was diagnosed with "Yang deficiency" due to rapid and tiny pulsation and reddish tongue without a coat.

\section{Treatments and course of symptoms}

This patient was hospitalized for 40 days. We supplied daily nutrition intravenously, including albumin or amino acids. An herbal drug, Gonjin-Dan (once a day), was given for care of her weakness during the whole hospital stay. At the beginning of hospitalization, we also prescribed Sayeok-Tang (three times a day) targeting the "Yang deficiency" and chilling sign. On the 5th day of taking Sayeok-Tang, the body temperature increased to $38.7{ }^{\circ} \mathrm{C}$ but there was no evidence of infection on physical examinations and laboratory testing. The fever led us to change the prescription to Soshiho-Tang (three times a day) for 2 days for antipyretic purpose (Figure 1 and Table 1). After the fever disappeared, Insamyangyeong-Tang (three times a day) was given for 33 days. We also provided high-protein meals throughout the hospitalization.

With Sayeok-Tang, anorexia improved quickly, resulting in an increase of the patient's food intake. However, Insamyangyeong-Tang was prescribed because her lethargy remained almost the same. Along with Insamyangyeong-Tang, lethargy began to improve and albumin also began to rise. Meanwhile, eosinophil began to rise above the normal range, but the patient did not feel any deterioration in itching symptoms. In addition, her biochemistry parameters improved, e.g., the serum albumin level improved to $2.8 \mathrm{~g} / \mathrm{dL}$ and the ALP 
level to $83 \mathrm{IU} / \mathrm{L}$, and the patient was discharged on hospital day 40. The patient felt improvements in general weakness, walking outside and diet, and gained weight approximately $0.5 \mathrm{~kg}(44.5 \mathrm{~kg}$ to $45.0 \mathrm{~kg}$ ). The fever did not recur during the hospitalization. During management as an outpatient for 5 months, we only did the laboratory tests, and there was no prescription for medication. The patient gained $2.0 \mathrm{~kg}$ more of body weight (45.0 $\mathrm{kg}$ to $47.0 \mathrm{~kg}$ ), and the eczema also improved moderately, with improvements in the $\mathrm{Hb}$ level $(11.7 \mathrm{~g} / \mathrm{dL})$ and the eosinophilia (4.8\%) (Figure 1 and Table 2).

\section{Discussion and Conclusion}

Edema or enlarged liver is a characteristic aspect of kwashiorkor, which can also be the criteria for clinician's diagnose. This 67-year-old woman was diagnosed with kwashiorkor as a form of PEM, based on the speed of symptom development and the laboratory results. This patient developed severe anorexia, tiredness, and general weakness, showed a lack of total protein and albumin, and showed fatty liver for 2 weeks after diarrhea therapy. In general, hypoalbuminemia is common in malnutrition. However, when combined with fatty liver, these are hallmarks of kwashiorkor. ${ }^{15)}$ The mechanism of its cause is unknown, but it is considered to originate from impaired energy production, impaired metabolic function, and oxidative stress due to the absence of nutrients. ${ }^{16,17)}$

Table 1. Composition of Drugs

\begin{tabular}{|c|c|}
\hline Drug & Composition $\left(\mathrm{g}^{*}\right)$ \\
\hline Gongjin-Dan & $\begin{array}{l}\text { Cervi Parvum Cornu (0.8), Angelicae Gigantis Radix (0.8), Corni Fructus ( } 0.8) \text {, Moschus berezovskii } \\
\text { Flerove (0.08), Apis mellifera Linné ( } 2 \text { ) }\end{array}$ \\
\hline Sayeok-Tang & Glycyrrhizae Radix et Rhizoma (6), Zingiberis Rhizoma (5), Aconiti Lateralis Radix Preparata (4) \\
\hline Insamyanyeong- Tang & $\begin{array}{l}\text { Paeoniae Radix (24), Zingiberis Rhizoma Recens (24), Angelicae Gigantis Radix (12), Cinnamomi } \\
\text { Cortex (12), Citri Unshius Pericarpium (12), Zizyphi Fructus (12), Ginseng Radix (12), Atractylodis } \\
\text { Rhizoma Alba (12), Astragali Radix (12), Glycyrrhizae Radix et Rhizoma (12), Anemarrhenae Rhizoma } \\
\text { (12), Rehmanniae Radix Preparata (9), Schisandrae Fructus (9), Saposhnikoviae Radix (9), Polygalae } \\
\text { Radix (6) }\end{array}$ \\
\hline
\end{tabular}

* The indicated dose is weight of each herb for an adult during one day

Table 2. Course of Laboratory Test Results

\begin{tabular}{|c|c|c|c|c|c|c|c|c|c|}
\hline \multirow{2}{*}{ Parameter } & \multicolumn{6}{|c|}{ Inpatient (week) } & \multicolumn{2}{|c|}{ Outpatient (week) } & \multirow{2}{*}{ Normal range } \\
\hline & 0 & 1 & 2 & 3 & 4 & 6 & 7 & 30 & \\
\hline Total protein $(\mathrm{g} / \mathrm{dL})$ & 5.6 & 5.7 & 6.1 & 6.2 & 6.7 & 6.5 & - & - & $6.6-8.7$ \\
\hline Albumin (g/dL) & 1.9 & 1.8 & 2.5 & 2.7 & 2.7 & 2.8 & - & - & $3.5-5.2$ \\
\hline $\operatorname{ALP}(\mathrm{U} / \mathrm{L})$ & 149 & 123 & 99 & 78 & 81 & 83 & - & - & $40-129$ \\
\hline WBC (103/ul) & 6.7 & 8.3 & 8.2 & 6.9 & 7.2 & 8.3 & 9.8 & 6.4 & $4.5-11.0$ \\
\hline Eosinophil (\%) & 14.0 & 9.5 & 12.5 & 22.9 & 28.2 & 33.0 & 41.2 & 4.8 & $<5$ \\
\hline Hemoglobin (g/dL) & 10.5 & 9.6 & 8.7 & 8.8 & 9.7 & 9.9 & 10.4 & 11.7 & $12-16$ \\
\hline $\operatorname{IgE}(\mathrm{IU} / \mathrm{mL})$ & 20955 & - & - & - & - & 19376 & - & - & $<1000$ \\
\hline
\end{tabular}

ALP: alkaline phosphatase, WBC: white blood cell, IgE: Immunoglobulin E 
In this case, the patient experienced severe diarrhea for 4 weeks, which was sufficient to induce the malabsorption of nutrients, leading to the inhibition of energy production and metabolic function.

In general, inadequate food intake, illness, nutrient loss, or poor nutrient absorption are common reasons for kwashiorkor, ${ }^{18)}$ and the diarrhea-dependent therapy process for uncontrolled atopic dermatitis induced the kwashiorkor condition in this case. Kwashiorkor often accompanies an electrolyte imbalance and hematological alterations, such as a low blood sodium level, anemia and low osmolarity by decreased albumin. ${ }^{19)}$ Rarely, the uncontrolled severe deficiency of albumin can lead to fluid leakage into tissue, which carries the risk of shock or even death. ${ }^{20)}$ Accordingly, we prescribed intravenous albumin and amino acid solutions in the early phase of treatment with the supply of a high-protein diet.

The $\mathrm{CBC}$ data showed a gradual decrease in the $\mathrm{Hb}$ level $(10.5$ to $8.7 \mathrm{mg} / \mathrm{dl})$ within the first 2 weeks, followed by improvements to $9.9 \mathrm{mg} / \mathrm{dl}$ (at discharge) and $11.7 \mathrm{mg} / \mathrm{dl}$ later. The $\mathrm{Hb}$ level decreased during the first 2 weeks of hydration such as intravenous albumin and amino acid solutions, but the level of $\mathrm{Hb}$ at the time of hospitalization $(10.5 \mathrm{mg} / \mathrm{dl})$ implies that it was a false figure due to severe dehydration condition. The high proportion of eosinophils $(14.0 \%$ to $33.0 \%$ ) was thought to be related to the severe atopic dermatitis. Skin disease, solid tumor, drug reactions, hematological tumor can be the reason of eosinophilia. However, atopic dermatitis is a well-known cause of eosinophilia, and this level of eosinophil is common in atopic dermatitis. ${ }^{21)}$ As shown in our case, both eosinophilia and high $\operatorname{IgE}$ levels are correlated with disease severity. ${ }^{22,23)}$ In this case, although the patient showed a pattern of an increasing eosinophil count by discharge, she presented with improved symptoms of itching. Of course, the eosinophilia showed changes toward normal on $\mathrm{CBC}$ analysis at 30 weeks.

Although malnutrition may be able to recover sufficiently with adequate nutrition, but in case of acute and severe malnutrition or even in elderly, it needs aggressive nutritional support and treatment. In Korean medicine theory, PEM which includes kwashiorkor, is a form of Heoro (虛勞, meaning fragile and weak). Repairing the fragile condition and strengthening the digestive system are the main strategies for treating PEM, for which we prescribed Sayeok-Tang, Insamyangyeong-Tang and Gongjin-Dan. Sayeok-Tang has been traditionally used for patients with collapse and lethargy. ${ }^{24}$ Insamyangyeong-Tang has shown anti-frailty effects by increasing energy production in the clinic, ${ }^{25)}$ while Gongjin-Dan has also been known to have anti-fatigue effects by regulating the hypothalamic-pituitary-adrenal axis. ${ }^{26)}$ We thought that these prescriptions would help the patient recover from severe kwashiorkor.

There have been several studies on herbal treatments for chronic malnutrition; ${ }^{12-14)}$ however, there have been no studies on kwashiorkor yet. Kwashiorkor sometimes becomes a challenging medical issue, and integrative treatment based on Korean medicine could be a promising strategy. This report provides useful information on the potential of Korean medicine for kwashiorkor. 


\section{Acknowledgement}

This study was supported by a grant of the National Research Foundation of Korea (NRF) funded by the Oriental Medicine R\&D Project (NRF-2018R1A6A1A03025221).

\section{References}

1. De Onis M, Monteiro C, Akré J, Glugston G. The worldwide magnitude of protein-energy malnutrition: an overview from the WHO Global Database on Child Growth. Bull World Health Organ. 1993;71(6):703.

2. Lochs H, Allison SP, Meier $\mathrm{R}$, et al. Introductory to the ESPEN guidelines on enteral nutrition: terminology, definitions and general topics. Clin Nutr. 2006;25(2):180-186.

3. Cereda E, Pedrolli C, Klersy C, et al. Nutritional status in older persons according to healthcare setting: a systematic review and meta-analysis of prevalence data using MNA ${ }$. Clin Nutr. 2016;35(6):1282-1290.

4. Healthcare Biagdata Hub. health insurance review \& assessment service. http://opendata. hira.or.kr/op/opc/olap4thDsInfo.do. Published 2019. Accessed February 10, 2019.

5. Puntis JWL. Malnutrition in Developed Countries. Ann Nestlé (English ed). 2009;67(2):65-72.

6. Pennington CR. Disease-associated malnutrition in the year 2000. Postgrad Med J. 1998; 74(868):65-71.

7. Béhar M, Viteri F, Bressani R, et al. Principles of treatment and prevention of severe protein malnutrition in childeren (kwashiorkor). Ann $N$ Y Acad Sci. 1958;69(5):954-968.
8. Longo DL, Fauci AS, Kasper DL, et al. Harrison's Principles of Internal Medicine. Vol 2012. Mcgraw-hill New York; 2012.

9. Boirie Y, Morio B, Caumon E, et al. Nutrition and protein energy homeostasis in elderly. Mech Ageing Dev. 2014;136:76-84.

10. Omran ML, Morley JE. Assessment of protein energy malnutrition in older persons, part I: History, examination, body composition, and screening tools. Nutrition. 2000;16(1):50-63.

11. Norman K, Pichard C, Lochs H, et al. Prognostic impact of disease-related malnutrition. Clin Nutr. 2008;27(1):5-15.

12. Kuniaki $H$, Akihiko $T$, Tetsuya $H$, et al. Improvement in Frailty in a Patient With Severe Chronic Obstructive Pulmonary Disease After Ninjin'yoeito Therapy: A Case Report. Front Nutr. 2018;5(September):3-6.

13. Ogawa-Ochiai K, Kawasaki K. Panax ginseng for frailty-related disorders: a review. Front Nutr. 2019;5:140.

14. Sasatani Y, Okauchi S, Ohara G, et al. Long-term maintenance of nutritional status with ninjinyoueito in terminal patients with chronic respiratory disease: Two case reports. Biomed Reports. 2020;12(3):121-124.

15. May T, Klatt KC, Smith J, et al. Choline supplementation prevents a hallmark disturbance of Kwashiorkor in weanling mice fed a maize vegetable diet: hepatic steatosis of undernutrition. Nutrients. 2018;10(5):653.

16. Fechner A, Böhme CC, Gromer S, et al. Antioxidant Status and Nitric Oxide in the Malnutrition Syndrome Kwashiorkor. Pediatr Res. 2001;49(2):237-243.

17. van Zutphen T, Ciapaite J, Bloks VW, et al. 
Malnutrition-associated liver steatosis and ATP depletion is caused by peroxisomal and mitochondrial dysfunction. J Hepatol. 2016; 65(6):1198-1208.

18. Saunders J, Smith T. Malnutrition: causes and consequences. Clin Med (Northfield Il). 2010; 10(6):624.

19. Frenk S. Metabolic adaptation in protein-energy malnutrition. J Am Coll Nutr. 1986;5(4):371-381.

20. G. Coulthard M. Oedema in kwashiorkor is caused by hypoalbuminaemia. Paediatr Int Child Health. 2015;35(2):83-89.

21. Okada R, Nakachi S, Inokuma S. The severity of peripheral blood eosinophilia indicates an eosinophilia- associated disease corresponding to its level. Allergol Int. 2016;65(1):112-114.

22. Walker C, Kägi MK, Ingold $P$, et al. Atopic dermatitis: correlation of peripheral blood $\mathrm{T}$ cell activation, eosinophilia and serum factors with clinical severity. Clin Exp Allergy. 1993; 23(2):145-153.

23. Trzeciak M, Gleń J, Bandurski $\mathrm{T}$, et al. Relationship between serum levels of interleukin-18, IgE and disease severity in patients with atopic dermatitis. Clin Exp Dermatol. 2011;36(7):728-732.

24. Lai F, Zhou G, Mai S, et al. Sini Decoction Improves Adrenal Function and the Short-Term Outcome of Septic Rats through Downregulation of Adrenal Toll-Like Receptor 4 Expression. Evid Based Complement Alternat Med. 2018; 2018:5186158.

25. Uto NS, Amitani H, Atobe $\mathrm{Y}$, et al. Herbal Medicine Ninjin'yoeito in the Treatment of Sarcopenia and Frailty. Front Nutr. 2018; 5:126.

26. Hong SS, Lee J, Lee JS, et al. The traditional drug Gongjin-Dan ameliorates chronic fatigue in a forced-stress mouse exercise model. $J$ Ethnopharmacol. 2015;168:268-278.

\section{ORCID}

Sul-Ki Kim https://orcid.org/0000-0001-5981-7849

Cheon-Hoo Jeon https://orcid.org/0000-0003-2474-412X

Chang-Gue Son https://orcid.org/0000-0003-4876-0167 